
Olguların Retrospektif Olarak Değerlendirilmesi

\title{
Retrospective Evaluation of Patients with Probable Cystic Echinococcosis to the Central Laboratory of the Kocaeli Derince Education and Research Hospital Between 2009 and 2011
}

\author{
Vesile Yazıcı ${ }^{1}$, Tahir Oruç², Elif Ören ${ }^{3}$, Hatice Ertabaklar ${ }^{4}$ \\ ${ }^{1}$ Kocaeli Derince Eğitim ve Araştırma Hastanesi, Tıbbi Mikrobiyoloji Kliniği, Kocaeli, Türkiye \\ ${ }^{2}$ Kocaeli Derince Eğitim ve Araştırma Hastanesi, Genel Cerrahi Kliniği, Kocaeli, Türkiye \\ ${ }^{3}$ Kocaeli Derince Eğitim ve Araştırma Hastanesi, Radyoloji Kliniği, Kocaeli, Türkiye \\ ${ }^{4}$ Adnan Menderes Üniversitesi Tıp Fakültesi, Parazitoloji Anabilim Dalı, Aydın, Türkiye
}

\section{ÖZET}

Amaç: Echinococcus granulosus'un etken olduğu Kistik ekinokokkozis (KE), dünyada ve ülkemizde yaygınlık gösteren zoonotik bir hastalık olup önemli bir halk sağlığı problemi olma özelliğini korumaktadır. Hastalığın ilimizdeki durumu ile ilgili ön bilgi edinmek için Kocaeli Derince Eğitim ve Araştırma Hastanesi Merkez Laboratuarı'na KE şüphesiyle gönderilen olguların retrospektif olarak değerlendirilmesi amaçlanmıştır.

Yöntemler: Aralık 2009-Mayıs 2011 tarihleri arasında laboratuarımıza başvuran toplam 225 olgunun Echinococcus granulosus indirekt hemaglutinasyon testi (IHA) sonuçları retrospektif olarak incelenmiştir. Pozitif olarak saptanan olgular geriye dönük olarak KE açısından klinik olarak değerlendirilmiştir.

Bulgular: Olguların 151'i (\%67.11) kadın, 74'ü (\%32.8) erkek olup IHA ile 18'inde (\%8) pozitif, beş olgu (\%2.2) borderline, geriye kalan 202 (\%89.8) olguda ise antikor yanıtı belirlenememiştir. Seropozitif ve borderline olarak saptanan 23 olgunun 15'inde radyolojik olarak KE ile uyumlu lezyon belirlenirken, dört olguda tutulum gösterilememiş, dört olgunun radyolojik bilgilerine ise ulaşılamamıştır.

Sonuç: Hastane kayıtlarının KE hastalığında olguların sadece az bir kısmını temsil ettiği düşünüldügünde ilimizde KE görüldüğü üzere varlığını sürdürdüğü ve önemini koruduğu anlaşılmaktadır. Bu nedenle gerek korunma gerekse hastalığın önlenmesinde gerekli önlemlerin alınması gerektiği görüşüne varılmıştır. (Turkiye Parazitol Derg 2012; 36: 219-21)

Anahtar Sözcükler: Kistik Ekinokokkozis, IHA, tanı

Geliş Tarihi: 21.05.2012

Kabul Tarihi: 31.10.2012

\section{ABSTRACT}

Objective: Cystic echinococcosis (CE) is caused by metacestodes of Echinococcus granulosus, which is one of the most widespread zoonotic diseases in humans in both developing and developed countries, and also in Turkey. The aim of this retrospective study was to evaluate the situation of hydatid disease in Kocaeli.

Methods: The specific anti-Echinococcus granulosus indirect haemagglutination test results of 225 patients, who were referred with probable CE to the Centre Laboratory of the Kocaeli Derince Education and Research Hospital during December 2009-May 2011 was assessed retrospectively. Positive cases were also reassessed clinically.

Results: Of the total, 151 (67.1\%) were female and 74 (32.8\%) were male. The seropositivity ratio of IHA test was found to be $8 \%$ (18 patients), borderline ratio as $2.2 \%$ (5 patients), and seronegative ratio as $89.8 \%$ (202 patients). In 15 of the 23 seropositive and borderline patients, CE compatible radiological lesions were determined, while 4 of the remaining patients showed no lesion and the other 4 had no radiological data. Conclusion: Considering that hospital records can represent only a small part of the CE cases, it can be said that CE still subsists and retains its importance in our city. Essential precautions should be taken for the prevention and protection for this disease. (Turkiye Parazitol Derg 2012; 36: 219-21)

Key Words: Cystic Echinococcosis, IHA, diagnosis

Received: 21.05.2012

Accepted: 31.10 .2012

Yazışma Adresi / Address for Correspondence: Dr. Vesile Yazııı, Kocaeli Derince Eğitim ve Araştırma Hastanesi, Tıbbi Mikrobiyoloji Kliniği, Kocaeli, Türkiye Tel: +90 2622335500 E-posta: vesileyazici@yahoo.com doi:10.5152/tpd.2012.53 


\section{GiRiş}

Kistik ekinokokkozis (KE) yurdumuzda büyük bir kesimin hayvancılıkla uğraşması, korunmada gerekli önlemlerin uygun şekilde alınamaması nedenleriyle gerek insanlarda gerekse sığır koyun gibi hayvanlarda yaygın görülen bir parazit hastalığıdır (1). İnsan kist hidatik hastalığı, insanda görülme oranı, ameliyatın ve tedavinin pahalı olması sebebiyle önemli bir sağlık sorunu oluşturmaktadır (1, 2). KE'in Eski Dünya'nın büyük bir kısmında, özellikle Yunanistan, Kıbrıs, Bulgaristan, Lübnan ve Türkiye'de; diğer bazı Avrupa ülkelerinde ve Afrika'da halen endemik olarak görüldüğü bildirilmektedir (3). Ülkemizde KE yaygın olarak görülmekle birlikte iç Anadolu, Doğu ve Güneydoğu Anadolu bölgelerinde daha sık görüldüğü belirtilmektedir $(4,5)$. KE'de organ lokalizasyonunun çoğunlukla karaciğer ve akciğer olduğu ve daha az sıklıkla dalak, kalp, beyin kemik ve diğer organlarda yerleşimin görüldüğü bilinmektedir (6).

Bu çalışmada ilimizdeki KE durumunu belirlemek amacıyla Aralık 2009-Mayıs 2011 tarihleri arasında Kocaeli Derince Eğitim ve Araştırma Hastanesi Merkez Laboratuarı'na KE şüphesiyle çeşitli kliniklerden gönderilen olguların Indirekt Hemaglütinasyon (IHA) testi sonuçları retrospektif olarak değerlendirilmiştir.

\section{YÖNTEMLER}

Çalışmamızda, Aralık 2009-Mayıs 2011 tarihleri arasında Kocaeli Derince Eğitim ve Araştırma Hastanesi Merkez Laboratuarı'na farklı kliniklerden KE şüphesiyle gönderilen 151'i kadın, 74'ü erkek, 225 hastaya ait serum örnekleri incelenmiştir. IHA testi ticari kit (Hydatidose, Fumouze Laboratoires, France) test prosedürüne uygun olarak çalışılmış̧ır. Serum sulandırımları U tabanlı mikroplaklarda 1/80, 1/160, 1/320 olmak üzere üç dilüsyon çalıșılmış (pozitiflik saptanması halinde 1/80, 1/160, 1/320, 1/640, 1/1280, 1/2560 olmak üzere altı sulandırım yapılmıştır) ve antijenli eritrosit süspansiyonu eklenerek, 2 saatlik inkübasyon sonrası düğme iliği şeklinde çökelti negatif, kenarı tırtıkı, dantela gibi görülmesi pozitif olarak değerlendirilmiştir. Test prosedürüne göre 1/320 ve üzerindeki değerler seropozitif, 1/160 sınır değer (borderline), 1/160'dan küçük değerler ise negatif olarak değerlendirilmiştir. Olguların yaş ve cinsiyete göre dağılımları retrospektif olarak değerlendirilmiştir.

\section{BULGULAR}

Yaşları 2 ile 84 yıl arasında değişen, yaş ortalaması: 32,5 olan toplam 225 olgunun IHA ile 18'i (\%8) pozitif, beş (\%2.2) olgu borderline, 202 (\%89.8) olgu ise negatif olarak saptanmıştır. Seropozitif olarak saptanan yaşları 11 ile 60 arasında değişen yaş ortalaması 36.6 olan olguların yedisini kadınlar $11^{\prime}$ 'ini ise erkekler oluşturmuștur. Borderline saptanan yaşları 22 ile 55 arasında değişen yaş ortalaması 36 olan olguların ikisini erkekler oluştururken, üçünü kadınlar oluşturmuştur. Seropozitif 13 olgu ve borderline 2 olgu olmak üzere yaşları 11 ile 60 arasında değişen yaş ortalaması 38.7 olan toplam 15 olguda radyolojik olarak (Batın US, Batın BT, Akciğer Direkt Grafi) KE ile uyumlu lezyon belirlenmiştir. Ikiyüz yirmi beş olgudan 108'i Kocaeli, dört olgu Sakarya, bir olgu Bolu, bir olgu Bursa, bir olgu Kars, bir olgunun Van'da ikamet ettiği belirlenirken dokuz olgunun adres bilgilerine ise ulaşılamamıştır.
Seropozitif olarak saptanan 18 olgunun $13^{\prime}$ 'ünde radyolojik olarak KE ile uyumlu lezyon belirlenirken, iki olguda tutulum gösterilememiş, üç olgunun radyolojik bilgilerine ise ulaşılamamıștır. Olguların 11'inde karaciğer tutulumu saptanırken, bir olguda böbrek tutulumu, bir olguda da akciğer tutulumu belirlenmiștir. Borderline olarak belirlenen 5 olgunun ikisinde radyolojik tutulum (karaciğer, dalak) gösterilirken, iki olguda tutulum gösterilememiş, bir olgunun ise bilgilerine ulaşılamamıştır.

Radyolojik tanı alan ve seropozitif ve borderline saptanan 15 olgunun yaş grubu ve cinsiyete göre dağlımları Tablo 1'de verilmiştir.

\section{TARTIŞMA}

Ülkemizde verilerin düzenli olarak toplanamaması veya eksik bildirilmesi sebebi ile Sağlık Bakanlığı verilerinin KE hakkında gerçeği tam olarak yansıtmadığı düşünülmektedir. Bu verilere göre 1975-1994 yılları arasında 40.242 olgu bildirilmiştir (1). Yazar ve ark. (7) 2001-2005 yılları arasında Türkiye genelinde yaptıkları çalışmada KE görülme oranını 6.3/100.000, Kocaeliınde ise $0.84 / 100.000$ olarak belirtmişlerdir. Karaman ve ark.'nın (8) Kars'ta yaptıkları çalışmada \%34.6 seropozitiflik oranı saptanırken cinsiyetler arasında anlamlı bir farka rastlanmadığı belirtilmiştir.

Todorov ve ark.'nın (9) 1999 yılında yayınlanan çalışmalarında Bulgaristan'da KE görülme oranı 3,3/100.000 olarak bildirmişlerdir. Türkiye genelinde yapılan çalışmalarda hastalığın kadınlarda daha fazla görüldüğünü bildiren çalışmalar bulunmaktadır. Akar ve ark.'nın (10) KE olgularını değerlendirdikleri çalısmalarında; saptanan 165 olgunun \%58'inin kadın, \%42'sinin erkek olduğunu; Özekinci ve ark.'nın (11) yaptıkları çalışmada saptanan 234 olgunun \%60.25'inin kadın, \%39.74'ünün erkek olduğunu bildirmişlerdir. Bununla birlikte enfeksiyonun her iki cinsiyette eşit oranlarda görüldüğünü bildiren çalışmalar da vardır (9). Çalışmamızda saptadığımız 15 olguda kadın erkek oranlarının birbirlerine yakın olduğu görülmüştür, buna göre KE olarak belirlenen olguların yedisini erkekler oluştururken, sekizini kadınların oluşturduğu saptanmıştır.

Değişik çalışmalarda KE olgularına her yaşta rastlanabildiği bildirilmişse de orta yaşlarda yüksek görülme oranı gösterdiği belirtilmiştir (12-14). Çalışmamızda saptanan olguların yaș dağılımı 11 ile 60 arasında değişmekle birlikte olguların \%33.33'ünü 20-40 yaş arasındaki olguların oluşturduğu saptanmıştır.

Ertabaklar ve ark.'ı (13), araştırmalarında KE olgularının \%66.4'ünde kistin karaciğerde, \%21.66'sında akciğerde ve $\% 0.83$ 'ünde dalakta yerleşim gösterdiğini tespit etmişlerdir.

Tablo 1. KE tanısı kesinleşen olguların yaş grubu ve cinsiyetine göre dağılımı

\begin{tabular}{|l|c|c|c|}
\hline Yaş Grupları & Erkek (\%) & Kadın (\%) & Toplam (\%) \\
\hline $10-20$ & $1(\% 6.67)$ & $1(\% 6.67)$ & $2(\% 13.33)$ \\
\hline $20-30$ & $2(\% 13.33)$ & $2(\% 13.33)$ & $4(\% 26.66)$ \\
\hline $31-40$ & - & $1(\% 6.67)$ & $1(\% 6.67)$ \\
\hline $41-60$ & $4(\% 26.66)$ & $3(\% 20)$ & $7(\% 47.67)$ \\
\hline $60-$ & - & $1(\% 6.67)$ & $1(\% 6.67)$ \\
\hline & $7(\% 47.67)$ & $8(\% 53.33)$ & $15(\% 100)$ \\
\hline
\end{tabular}


Ertuğ ve ark.'ı (14), Aydın ve çevresinde yaptıkları çalışmalarında karaciğer lokalizasyonunun \%89.3 ile birinci sırada, akciğer lokalizasyonunun ise \%7.1 ile ikinci sırada yer aldığını bildirmişlerdir. Delibaş ve ark.'nın (12), yaptıkları çalışmada KE ön tanısıyla operasyon geçiren olgular arasında en sık tutulan organlar sırasıyla karaciğer \%70 ve akciğer \%11 olarak belirtilmiştir. Bu çalışmalarda olduğu gibi bizim çalışmamızda da, radyolojik tanı alan ve seropozitif ve borderline saptanan olguların \%73.33'ünde karaciğer tutulumu en sık olarak belirlenirken, \%6.66'sında akciğer, \%6.66'sında böbrek, \%6.66'sında dalak tutulumu gösterilmiştir.

Kist hidatik tanısı karaciğer enfeksiyonu için ultrason veya bilgisayarlı tomografi (BT) taraması ile yada akciğer enfeksiyonları için göğüs filmi veya BT ile yapılmaktadır. Görüntüleme yöntemleri ile birlikte serolojik yöntemlerin de kullanılmasının tanıda hassasiyeti arttırdığı bilinmektedir (1).

Klinik tanıda KE'in diğer kitleler ile karıştırılması sebebiyle hastanın hikayesinin tanıda öneminin büyük olduğu bildirilmektedir (15). IHA testinin duyarlılık ve özgüllüğünün diğer serolojik testlerle karşılaştırıldığında daha yüksek olduğu belirtilmektedir (16). Sarı ve ark.'nın (17) yaptıkları çalışmada KE olduğu kanıtlanmış olgularda IHA testinin \%97.5 özgül, \%90 duyarlı, Bilge ve ark.'nın (18) yaptıkları çalışmada IHA testinin \%100 özgül, \%74.6 duyarlı olarak bildirilmiştir. Serolojik tanıda kullanılan testlerin duyarlılık ve özgüllüğünün kullanılan kitin özelliklerine, kistin yerleşim yeri ve sayısı, antijenin özelliklerine, antijenin elde edildiği konağa, hastanın antikor yanıtına, seçilen yönteme göre değiştiği bildirilmiştir (18-20). Serolojik testlerin duyarlılık ve özgüllüğünü arttırmak için aynı serum örneğinin farklı yöntemlerle çalışılması önerilmektedir $(19,20)$.

Ayrıca KE serolojik tanısında çeşitli yöntemler kullanılmaktadır. IHA ve ELISA yöntemlerinin kolay uygulanabilmesi, pahalı laboratuvar gereçleri gerektirmemesi, yüksek özgüllük ve duyarlılıkları nedenleri ile sıklıkla IHA ve ELISA yöntemleri tercih edilmekte$\operatorname{dir}(12,17,21)$. Biz de laboratuarımızda bu nedenle IHA yöntemini KE serolojisinde kullanmaktayız.

Ilimizde görüldüğü üzere kısa bir zaman diliminde sadece hastanemiz Merkez Laboratuvarına başvuran olgular değerlendirildiğinde KE olgularının azımsanamayacak sayıda olduğu görülmektedir. Saptadığımız olguların ildeki genel durumu yansıtması mümkün olmamakla birlikte fikir vermesi açısından anlamlı olduğu düşünülmektedir. Saptadığımız olguların gerçek olgu sayısının sadece küçük bir bölümünü oluşturduğu düşünüldüğünde gerçek olgu sayısının çok daha fazla olduğu yadsınamayacak bir gerçek olup gerçek durumu saptamak amacı ile yapılacak epidemiyolojik çalışmalara ihtiyaç duyulmaktadır. Enfeksiyon Doğu ve Güney Doğu Anadolu bölgelerine göre düşük oranda saptanmakla birlikte bölgemizde önemli bir halk sağlığı sorunu oluşturan ve ekonomik kayba neden olan bu hastalığın eradikasyonu için korunma ve kontrol programlarının planlı bir şekilde yapılması ve toplumun bilinçlendirilmesi gerektiği kanaatine varılmıştır.

\section{Çıkar Çatışması}

Yazarlar herhangi bir çıkar çatışması bildirmemişlerdir.

\section{KAYNAKLAR}

1. Özbilgin A, Kilimcioğlu AA. Kistik Echinococcosis. Özcel MA. ed. Özcel'in Tıbbi Parazit Hastalıkları. Bornova: Meta Basım Matbaacılık Hizmetleri; 2007.p.541-66.
2. Garcia HH, Jimenez JA, Escalante H. Sestodlar Murray PR, Baron EJ, Landry ML, Jorgensen JH, Pfaller MA. eds. Klinik Mikrobiyoloji. Dokuzuncu baskı. Ankara: Atlas Kitapçlık; 2009.p.2166-75.

3. Eckert J, Deplazes P. Biological, epidemiyological and clinical aspects of echinococcosis, a zoonozis of increasing concern. Clin Microbiol Rev 2004; 17: 107-35. [CrossRef]

4. Altıntaş N. Past to present: Hydatidosis/ echinococcosis in Turkey. Acta Tropica 2003; 85: 105-12. [CrossRef]

5. Kilimcioğlu A, Ok UZ, İnsanda Echinococcus türlerinde coğrafik yaygınlık ve Türkiye'deki durum, Altıntaş N, Tınar R, Çoker A, editors. Echinococcosis, İzmir: Ege Üniversitesi Matbaası; 2004.p.129-40.

6. Khuroo MS, Wani NA, Javid G, Khan BA, Yattoo GN, Shah AH, et al. Percutaneous drainage compared with surgery for hepatic hydatid cysts. N Engl J Med 1997; 337: 881-7. [CrossRef]

7. Yazar S, Ozkan AT, Hökelek M, Polat E, Yilmaz H, Ozbilge H, et al. [Cystic echinococcosis in Turkey from 2001-2005]. Turkiye Parazitol Derg 2008; 32: 208-20.

8. Karaman U, Mıman O, Kara M, Gicik Y, Aycan OM, Atambay M. [Hydatid cyst prevalence in the region of Kars.]. Turkiye Parazitol Derg 2005; 29: 238-40.

9. Todorov T, Boeva V. Human echinococcosis in Bulgaria: a comparative epidemiological analysis. Bull World Health Organ 1999; 77: 110-8.

10. Akar Ş, Üner. A. İzmir Atatürk Eğitim ve Araştırma Hastanesinde saptanan uniloküler kistik ekinokokkozis olgularının retrospektif olarak değerlendirilmesi. Turkiye Parazitol Derg 2001; 25: 349-52.

11. Ozekinci S, Bakir S, Mizrak B. [Evaluation of cystic echinococcosis cases given a histopathologic diagnosis from 2002 to 2007 in Diyarbakir]. Turkiye Parazitol Derg 2009; 33: 232-5.

12. Delibaş SB, Ozkoç S, Sahin S, Aksoy U, Akisü C. [Evaluation of patients presenting with a suspicion of cystic echinococcosis to the serology laboratory of the Parasitology Department of Dokuz Eylül University Medical Faculty]. Turkiye Parazitol Derg 2006; 30: 279-81.

13. Ertabaklar H, Pektaş B, Turgay N, Yolasığmaz A, Dayangaç $M$, Özdamar A, ve ark. İzmir ve çevresindeki hastanelerde Ocak 1997 Mayıs 2001 arasında saptanan kistik ekinokokkozis olguları. Türkiye Parazitol Derg 2003; 27: 125-8.

14. Ertuğ S, Sarı C, Gürel M, Boylu Ş. Çanakkalelioğlu L, Şahin B. Aydın ve çevresinde 1996-2000 yılları arasında cerrahi olarak saptanan kist hidatik olguları. Turkiye Parazitol Derg 2002; 26: 254-6.

15. Şahin I. Sestodlar. Ustaçelebi Ş, Mutlu G, İmir T, Cengiz AT, Tümbay E, Mete Ö editors. Temel ve Klinik Mikrobiyoloji, Birinci baskı. Ankara: Güneş Kitapevi; 1999.p.1241-53.

16. Eşgin $M$, Aktaş $M$, Coşkun $S$. [The investigation of antibody presence in the sera of patients with a suspicion of cystic echinococcosis by using indirect hemaglutination test (IHA)]. Turkiye Parazitol Derg 2007; 31: 283-7.

17. Sari C, Ertuğ S, Karadam SY, Ozgün H, Karaoğlu AO, Ertabaklar H. [The comparative evaluation of Enzyme Linked Immunosorbent Assay (ELISA), Indirect Hemagglutination Test (IHA) and Indirect Fluorescent Antibody Test (IFAT) in the diagnosis of cystic echinococcosis]. Turkiye Parazitol Derg 2009; 33: 73-6.

18. Bilge UE, Ozdemir M, Baykan M. [Comparison of commercial IFA, IHA and in-house IFA tests in the diagnosis of cystic echinococosis]. Turkiye Parazitol Derg 2009; 33: 195-8.

19. Abdel Aal TM, El-Hady HM, Youssef FG, Fahmi IA, Abou El-Saoud $\mathrm{SM}$. Studies on the most reactive purified antigen for immunodiagnosis of hydatid disease. J Egypt Soc Parasitol 1996; 26: 297 303.

20. Gottstein B. Molecular and immunological diagnosis of echinococcosis. Clin Microbiol Rev 1992; 5: 248-61.

21. Biava MF, Dao A, Fortier B. Laboratory diagnosis of cystic hydatic disease. World J Surg 2001; 25: 10-4. [CrossRef] 